UNDERGRADUATE RESEARCH IN NATURAL AND CLINICAL SCIENCE AND TECHNOLOGY (URNCST) JOURNAL Read more URNCST Journal articles and submit your own today at: https://www.urncst.com

\title{
Stress-Related Socioeconomic Factors and Risk of Alzheimer's Disease: A Literature Review
}

Swati Anant, BHSc Student [1]*, Nicholas Lum, BHSc Student [1], Tina Wu, BHSc Student [1]

[1] Department of Health Sciences, McMaster University, Hamilton, Ontario, Canada L8S 4L8

*Corresponding Author: anants2@mcmaster.ca

\begin{abstract}
Introduction: Recent studies have proposed an association between chronic stress and an increased risk of Alzheimer's Disease $(A D)$ and other dementias. AD pathology has been linked to elevated amyloid $\beta(A \beta)$ production and formation of $\mathrm{A} \beta$ plaques. A key indicator of chronic stress is high cortisol levels, which have also been shown to amplify amyloid $\beta$ production, thus making chronic stress a risk factor for AD. A number of risk factors for chronic stress development, including socioeconomic variables have also been suggested as potential risk factors for AD. However, the link between socioeconomic factors, chronic stress and $\mathrm{AD}$ incidence remains unclear. This review examines how education, income levels and occupation status may influence the relationship between chronic stress and AD risk.

Methods: We reviewed the literature examining the relationship between occupation, education, and income with stress and AD risk. We performed a thorough search of PubMed, Medline, Web of Science and PsycInfo using predefined keywords, prioritizing prospective cohort studies that primarily examined $\mathrm{AD}$, but also included articles on vascular dementia.

Results: Job strain and increased mental demands at work are associated with increased AD risk. Low income is associated with multiple comorbidities, which is further associated with adverse AD. Additionally, higher education is correlated with decreased $\mathrm{AD}$ risk, but independently of the relationship between psychological stress and $\mathrm{AD}$.

Discussion: Literature suggests that chronic stress is related to AD risk, but this relationship is complicated when considering stress-related factors including occupation, education and income. Our review demonstrates that further research must be conducted on this topic to elucidate the correlation between socioeconomic factors, chronic stress and AD risk.

Conclusion: This study will contribute to our understanding of how occupation, education level and income impact AD risk and advocate for methods in closing the health disparity through socioeconomic disparity.
\end{abstract}

Keywords: psychological stress; Alzheimer's disease; dementia; socioeconomic status; education; income; occupation; chronic stress; cognitive reserve; job strain

\section{Introduction}

Alzheimer's disease (AD), the most common form of dementia, is a neurodegenerative disease affecting approximately 44 million people worldwide [1]. It is characterized by the progressive cognitive decline, resulting in the disruption of daily life and irreversible brain damage [2]. $\mathrm{AD}$ is most prevalent among older adults, and individuals with $\mathrm{AD}$ survive roughly 4-8 years following diagnosis [3]. The pathogenesis of $\mathrm{AD}$ has been linked to two main lesions: senile plaques, which are small, dense deposits of amyloid $\beta(\mathrm{A} \beta)$ protein that interfere with nerve signal transduction and increase the extent of neurological damage in $\mathrm{AD}$ patients, and neurofibrillary tangles composed of Tau protein, which hinder neural communication and prevent adequate levels of nutrients from reaching neurons $[2,4]$.

Additional insight into how this disease develops may be observed through identification of risk factors such as age, genetics, and cardiovascular disease. Studies have also found that susceptibility to experiencing psychological stress is a risk factor for $\mathrm{AD}$ [3,5]. However, there is limited research examining this relationship. Chronic stress refers to a recurring response generated from heightened emotional arousal, which can lead to the perception of a loss of control. The progressive accumulation of chronic stress is an important factor to consider in the onset of $\mathrm{AD}$ [6]. Stress is often measured in a clinical setting through physiological variables such as cortisol, or via self-reported questionnaires [6].

The role of stress in the pathogenesis of $\mathrm{AD}$ has been examined in various studies. Excessive stress can exacerbate AD progression through elevated levels of stress hormones [7]. Specifically, corticosteroids and corticotropin releasing factors were found to increase $A \beta$ production and plaque formation. In $\mathrm{AD}$ animal models, stress has been shown to accelerate cognitive decline. In rats and mice, stress elevated $\mathrm{A} \beta$ peptide production and increased its deposition into amyloid plaques [7]. Another way in which stress has been 
UNDERGRADUATE RESEARCH IN NATURAL AND CLINICAL SCIENCE AND TECHNOLOGY (URNCST) JOURNAL Read more URNCST Journal articles and submit your own today at: https://www.urncst.com

linked to AD onset is through the inflammation of microglia. Microglia are the predominant immune cells necessary in maintaining central nervous system homeostasis. These cells respond to alterations in brain homeostasis caused by chronic stress, and have been linked to neuroinflammation, which has also been causally linked to $A \beta$ accumulation and Tau pathology [8].

There are a variety of socioeconomic variables that may predispose individuals to a higher number of stress-inducing events, which may contribute to increased AD risk. Socioeconomic status (SES) is a widely known determinant of health outcomes, yet research conducted in this field as it relates to $\mathrm{AD}$ has been sparse [9]. The American Psychological Association describes SES as the class or social standing of an individual or group [10]. This review aims to clarify whether socioeconomic factors thought to be related to stress-namely income, education, and occupation - may influence the relationship between chronic stress and risk of AD. Establishing this correlation will inform development of policies to diminish socioeconomic disparities, thus reducing the prevalence of $\mathrm{AD}$.

\section{Methods}

A thorough search of PubMed, Medline, Web of Science and PsycInfo was performed with the keywords listed below:

Psychological stress*, dementia*, Alzheimer*, socioeconomic, chronic stress*, employment*, income*, education*

We prioritized studies summarizing all three components of stress, socioeconomic factors, and AD risk in their results. In total, 22 articles were reviewed. Studies that specifically discussed $\mathrm{AD}$ were prioritized, however, articles focusing on other dementias were not excluded. If there was a lack of articles correlating all three socioeconomic measures, we included the most cited source that drew an association between two of the three components to draw inferences about how all the components were related. Observational studies were prioritized in this review, although systematic reviews were not excluded. Articles published earlier than 2000 were excluded from our search in order to include modern definitions of $\mathrm{AD}$, and account for the modern conceptions of the social determinants of health.

\section{Results}

Occupation

The correlation between occupation and AD risk mediated by work-related stress has been highlighted in the available literature. Andel et al. published a study examining the relationship between work-related stress and dementia, vascular dementia, and Alzheimer's disease [11]. Participants were members of the Swedish Twin Registry, a population-based registry of twins residing in Sweden. In this study, occupation was measured through indicators of work-related stress derived from Karasek's job strain model, which postulates that psychological strain is the product of job demands and range of decision-making abilities [11,12]. Job demands were defined as the workload stressors experienced, such as work schedule intensity. Job control was defined as the extent to which one exercises personal judgment in their job. Social support was defined as the possibility for helpful social interaction, and job strain was indicated by the ratio of job demands to job control [11,12]. Results from this study indicated lower job control and lower social support was associated with greater risk of vascular dementia, a condition that occurs as a result of aging of the cardiovascular system, which is linked to AD onset. Greater job strain was linked to an increased risk of vascular dementia [11].

A study in 2012 conducted by Wang et al. examined how high job stress during working life might lead to an increased risk of $\mathrm{AD}$ and non- $\mathrm{AD}$ dementias (NAD) later in life [13]. Healthy older adults at baseline were followed up for an average of 6 years to detect incident AD and NAD. Occupational data was collected at the first follow-up of the longitudinal study, typically through an informant who answered questions about life-span work activities. Job demands, job control, and job support were evaluated. Individuals diagnosed with dementia due to $\mathrm{AD}$ or other etiologies after follow-up were older, less educated, had lower job demands, and lower job control than those who did not develop dementia. Furthermore, this study indicated those who had high job strain (i.e., those in jobs with high demands and low decision latitude) were often welleducated females [13]. When Wang et al. controlled for work complexity, the association between passive job strain and dementia risk was weakened. It was concluded that both under stimulation and overstimulation may impact $\mathrm{AD}$ risk [13].

Finally, Sundstrom et al. examined how high mental demands at work might be a protective factor in reducing risk of dementia and $\mathrm{AD}$ [14]. In a prospective cohort study, healthy older adults without dementia were asked to complete an examination to determine cognitive function at baseline. At the end of the study, of the 1277 participants, 199 individuals $(15.5 \%)$ developed $\mathrm{AD}$, and 145 individuals (11.4\%) developed vascular dementia. Occupational information was obtained through questionnaires about socioeconomic factors, such as main lifetime occupation and description of its job characteristics. Unlike the previous two studies examined, this study revealed no association between workplace mental demands and dementia or AD risk [14].

\section{Income}

Studies have indicated a correlation between income and AD-related outcomes. Income-related lifestyle factors, chronic disease, and psychological disorders were identified as main contributors to AD. However, such studies do not explicitly examine the relationship between these two variables as it relates to stress. Stepkowski et al. found a 
UNDERGRADUATE RESEARCH IN NATURAL AND CLINICAL SCIENCE AND TECHNOLOGY (URNCST) JOURNAL Read more URNCST Journal articles and submit your own today at: https://www.urncst.com

negative correlation between per capita personal income and age-adjusted $\mathrm{AD}$ death rates such that those with higher income had lower death rate from $\mathrm{AD}$ [15]. Income had a significant, lifelong influence on the risk of $\mathrm{AD}$ development, found to be highest in the early years of life. In a cohort study by Chen et al. that assessed the effects of income-related insurance payments on AD survival outcomes, patients with $\mathrm{AD}$ and low individual payments displayed the lowest survival rate [3]. After adjusting for confounding variables, the mortality risk of patients with high income in disadvantaged geographic areas remained similar to those with high income in advantaged areas, indicating individual earnings are of greater importance regarding $\mathrm{AD}$ mortality.

Another study by Kumar et al. assessed the association between income-based disparities, chronic disease, and cognitive functioning in older adults [16]. The authors used the India dataset from the World Health Organization Study on global AGEing and adult health (SAGE). SAGE assesses older adult cognition by generating an overall cognition score, which was used in a two-level linear hierarchical model to record its association with SES at individual and community levels. Household income and community level SES were found to be positively correlated with cognition whereas multimorbidity was negatively associated with cognition. Interestingly, this paper cited that those living in deprived communities are more vulnerable to many adverse outcomes including mental disorders such as anxiety [17].

Provided that communities of lower income status are more susceptible to health problems, a connection could be bridged between a low-income environment and the development of neurodegenerative disease. In a study conducted by Huang et al., data from 13,067 individuals with major depressive disorder (MDD) and 52,268 nonMDD controls were extracted from Taiwan's National Health Insurance Research Database and matched through propensity score [18]. The patients were followed up until dementia diagnosis, death, or end of 2013 to assess outcomes. The primary outcome was dementia incidence, which was further classified into an $\mathrm{AD}$ group and a NAD group. Compared to the non-MDD group, individuals with MDD were 4.7 times more likely to develop AD, and 3.7 times more likely to develop NAD. This indicates a correlation between low income and increased risk of adverse outcomes in $\mathrm{AD}$ and other dementias. In contrast with these findings, a case-control study analyzed the effects of physical and social environments on dementia incidence and found higher odds of dementia in areas with high median annual family income, although a significant relationship did not appear after further adjustment for confounding variables [19].

\section{Education}

Many correlational studies have found a negative association between years of formal education and AD risk.
The bulk of the literature considers stress and education as separate factors influencing risk of $\mathrm{AD}$, and such studies have yet to explore how these two variables interact. Russ et al.'s meta-analysis explored how SES in early life and adulthood may be associated with dementia-related death. Psychological distress was measured as a covariate using the General Health Questionnaire. Low educational attainment was linked to a heightened risk of dementiarelated death, but this relationship was only observed in women [20].

A main focus of the literature examining the relationship between education and $\mathrm{AD}$ is the cognitive reserve $(\mathrm{CR})$ hypothesis. CR describes the use of cognitive processes to cope with the symptoms of neurodegenerative disease: for instance, switching to an alternative function when the default function is inoperable [21]. In addition to educational attainment, lifetime exposures that can increase CR include musicianship, bilingualism, and exercise [22]. Notably, Qiu et al. conducted a longitudinal study on older adults without dementia and found a correlation between low levels of education and increased incidence of clinical AD, which is consistent with the CR hypothesis [23]. Additionally, in a prospective cohort study by Scarmeas et al. examining incident $\mathrm{AD}$ cases over the course of 14 years, higher education was correlated with a faster rate of cognitive decline, particularly concerning executive speed and memory [24]. Researchers hypothesize that this faster rate of decline supports the CR hypothesis, as it signifies that the manifestation of symptoms in individuals of higher education occurs further along in their disease progression, when cognitive decline more sharply decreases, compared to those without higher education. Despite the plethora of research on the CR hypothesis, very few studies have explored its relationship with stress. A cross-sectional study by Cabral et al. found no association between measures of cortisol, selfreported stress, and CR in healthy older adults [25]. Stress and $\mathrm{CR}$ independently contributed to the development of $\mathrm{AD}$, but $\mathrm{CR}$ did not modulate the relationship between stress and risk of cognitive decline [25].

\section{Discussion}

The aim of this paper was to clarify the intercorrelations between chronic stress, socioeconomic factors and $\mathrm{AD}$ risk. A thorough literature search was performed examining relationships between education, income, occupation, stress, and AD. The rationale behind linking socioeconomic factors to $\mathrm{AD}$ via stress was due to a previously established link between stress with AD risk, and socioeconomic factors with later life stress.

With regards to occupation, few studies examined how work-related stress impacted AD risk via job strain. The findings of Andel et al. along with those of Wang et al., demonstrated that lower levels of job control are associated with an increased risk of dementia. This concept supports the CR hypothesis, in which increased mental demands at work may facilitate development of cognitive skills, such as 
UNDERGRADUATE RESEARCH IN NATURAL AND CLINICAL SCIENCE AND TECHNOLOGY (URNCST) JOURNAL Read more URNCST Journal articles and submit your own today at: https://www.urncst.com

problem-solving and memory, that may serve as protective factors in dementia risk. However, there is an important difference between two of the studies examined with regards to how they proposed stress to interact with occupation and risk of AD [11,13]. First, Andel et al., proposed a cardiovascular pathway mediated by stress underlying the relation between job control and increased dementia risk. Andel et al., showed that job strain was associated with vascular dementia, a condition that arises due to accelerated aging of the cardiovascular system [11]. Thus, a cardiovascular pathway mediated by stress would account for the risk of vascular dementia proposed in this study. In addition, this cardiovascular pathway is the result of chronic stress and leads to a dysregulation of other organ systems. On the contrary, Wang et al. proposed a mechanism involving acute stress which would entail increasing cortisol secretion, producing short-term damage in the hippocampus. Indeed, repeated experiences of stress causes atrophy of the dendrites of pyramidal neurons in the hippocampus [11]. This mechanism is plausible in the context of Wang et al.'s study seeing as job strain was not associated with vascular dementia, indicating that noncardiovascular mechanisms may be involved in the relationship. When Andel et al. controlled for work complexity, the association between the lack of social support at work and dementia was strengthened. This suggests that including more occupational health and wellness policies may reduce dementia risk, such as those that increase autonomy in order to increase job control, facilitate communication and social support systems, and modify job demands [11]. Wang et al., on the other hand, found that both understimulation and overstimulation may impact $\mathrm{AD}$ risk, which suggests that a balance must be found in the workplace to ensure employees are completing fulfilling work requirements while also mitigating stress levels. This strategy may involve encouraging collaboration to reduce the workload for individuals and promoting positive relationships while accomplishing tasks with the same, or perhaps higher degree of quality [13]. Sundstrom et al., highlighted some important limitations in both Andel et al.'s and Wang et al.'s work, including their small sample sizes which were subject to selection bias, and that $\mathrm{AD}$ prevalence was examined rather than incidence $[13,14]$. Sundstrom et al. examined a relatively homogenous population in Sweden, reducing the presence of selection bias. The discrepancy between these findings and previous ones likely lies in the variability in study design, statistical methods and adjustment for covariates. An advantage of Sundstrom et al.is the large sample size and follow-up time, along with its random sampling methods. However, there is a lack of detail explaining how socioeconomic factors influence the relationship between stress and dementia risk. Of the three studies, Andel et al. provided the most thorough investigation of the influence of each covariate, and the results were strengthened by the multiple controls utilized $[11,13,14]$.

Anant et al. | URNCST Journal (2021): Volume 5, Issue 1 DOI Link: https://doi.org/10.26685/urncst.206
In terms of income, the consensus is that individuals with lower income-related SES are more likely to develop $\mathrm{AD}[3,15]$. However, one study by Liu et al. shows that increased dementia incidence was observed in areas with high medial annual family income, although this relationship was not deemed significant after adjusting for confounding variables [19]. The studies that do establish an association do not mention how stress may mediate this relationship. Stepkowski et al. and Chen et al. found statistically significant correlations between income level and risk for both $\mathrm{AD}$ and non-AD dementias [3,15]. Stepkowski et al. postulate income-related modifiable lifestyle factors largely determine the likelihood of AD [15]. These modifiable risk factors such as smoking, physical activity, alcohol consumption, isolation, sleep disturbance, and diet need to be addressed, particularly amongst those who are financially disadvantaged. Interestingly, Chen et al. found that individual income is a greater determinant of AD mortality than community income [3]. This indicates that socioeconomic support should be allocated on an individual case-by-case basis rather than by community. In addition to finding an association between economic disadvantage and lower cognition, Kumar et al. also found that higher multimorbidity was correlated with a decrease in cognition and noted that lower-income communities are more vulnerable to health problems than higher-income communities [16]. Other studies, such as those by Vassilaki et al. and Villeneuve et al. have observed a positive relationship between multimorbidity and dementia [26,27]. Furthermore, Kumar et al. proposed that those with lower income are more susceptible to anxiety, and Huang et al. found that patients with MDD had higher risks of both AD and NAD compared to those without MDD [16,18]. Considering that multimorbidity is associated with increased risk of neurodegenerative diseases, this research paves way for future studies to establish a more concrete link between income, $\mathrm{AD}$, and stress-related health problems. Therefore, stress is likely only one piece of a larger multimorbidity puzzle that bridges income and $\mathrm{AD}$, as hinted by Huang et al. and Kumar et al. More research needs to be conducted to clearly establish relationships between these variables.

The relationship between education and AD risk is well established in the literature, however this link often does not account for stress. To summarize, the meta-analysis conducted by Russ et al. found an association between leaving full-time education earlier in life and risk of dementia-related death after adjusting for psychological distress, but only in women [20]. The study highlights the importance of intervention strategies for women, who generally have a higher risk of dementia than men [28]. The promotion of higher education in women may become an important topic in public health. Nevertheless, the effect of education on $\mathrm{AD}$ risk in females needs further research. Additionally, this study had the benefit of a large, well- 
UNDERGRADUATE RESEARCH IN NATURAL AND CLINICAL SCIENCE AND TECHNOLOGY (URNCST) JOURNAL Read more URNCST Journal articles and submit your own today at: https://www.urncst.com

characterized sample that was representative of the general population of England. However, there were only 622 dementia-related deaths, since it included a wide age range of individuals 35 and older [20]. A sample with such variability in age allows for greater generalizability, but lacks specificity to $\mathrm{AD}$ as the age of onset for most cases is above 65 [3]. A final critique of the study is that dementia is often under-recorded as the cause of death [29]. Thus, studies that confirm dementia diagnosis through other methods may be more reliable, such as a combination of neuropsychological assessment with neuro-imaging techniques of MRI or CT scan, as seen in Scarmeas et al's study.

Furthermore, the protective association between education and $\mathrm{AD}$ risk was suggested through the $\mathrm{CR}$ hypothesis by various researchers. Qiu et al.'s study found an increased $\mathrm{AD}$ risk in those with lower educational attainment, with the effect more evident in women than in men, consistent with Russ et al.'s findings [20,23]. However, Qiu et al.'s sample included only 109 participants who were diagnosed with AD. While Russ et al.'s study had the issue of measuring dementia prevalence through death certificates, this study examines incident AD cases $[20,22]$.

Another study found that individuals with AD who received higher education experience faster cognitive decline after diagnosis than individuals without higher education. The study proposes that individuals with higher education can better manage the pathological burden and mask symptoms of AD. When this population does show measurable cognitive decline, they are further along the disease progression and show faster cognitive decline than their peers with lower education, supporting the CR hypothesis [24]. However, follow-up post diagnosis in the study was relatively limited (1.8 years), so the full progression of cognitive decline may not have been captured [24]. Finally, no association was found between CR with stress in Cabral et al.'s cross-sectional study, which included a relatively small sample size of 145 individuals [25]. The study was conducted on healthy older adults rather than individuals with dementia-related diseases, making the findings generalizable to prodromal rather than severe $\mathrm{AD}$ [25]. The variability of methodologies across studies that use incident cases of AD, prevalent cases, and healthy older adults may contribute to inconsistencies in findings of how education and stress impact AD risk. Additionally, studies only accounted for the quantity of education and not quality; the difference between homeschooling, public, and private education was not researched.

\section{Conclusions}

The aim of this paper was to clarify how education level, income, and occupation influence the relationship between chronic stress and risk of AD. We hypothesized that since chronic stress has been shown to correlate with
$\mathrm{AD}$, socioeconomic factors related to high levels of chronic stress will influence $\mathrm{AD}$ risk. Our review suggests further research, potentially in the form of prospective cohort studies, must be conducted in order to validate this correlation. For occupation, findings are mixed, as some studies suggest a relationship between mental demands at work and risk of $\mathrm{AD}$, while other studies suggest that increased job strain is associated with a greater risk of developing $\mathrm{AD}$. Low income was correlated with adverse $\mathrm{AD}$ outcomes, however, stress is not the only factor mediating this relationship_multi comorbidities may be primarily responsible. Finally, education affects AD risk through a mechanism separate from stress, with the CR hypothesis at the forefront of research. With all three socioeconomic factors, only correlational relationships could be effectively established due to the nature of the studies. Overall, SES is correlated with AD, but occupation was the only factor for which a stress-related pathway was proposed. Although stress may not be involved in the relationship between income, education, and $\mathrm{AD}$, the present review suggests future directions of research in ways to mitigate AD risk. Suggested methods have included higher levels of social support at work, encouraging the pursuit of higher education, and addressing socioeconomic disparities by improving access to education and bridging health inequities. Stress reduction activities throughout one's lifetime could also promote healthy aging. Overall, more research in this field will help to gain a stronger understanding of how socioeconomic factors impact $\mathrm{AD}$ incidence and equip older adults with strategies and lifestyle changes to reduce their risk of $\mathrm{AD}$.

\section{List of Abbreviations Used}

A $\beta$ : amyloid $\beta$

AD: Alzheimer's disease

$\mathrm{CR}$ : cognitive reserve

MDD: major depressive disorder

NAD: non-Alzheimer's dementia

SAGE: Study on global AGEing and adult health

SES: socioeconomic status

\section{Conflicts of Interest}

The authors declare no conflict of interests.

\section{Ethics Approval and/or Participant Consent}

The study did not require ethics approval or participant consent. As a literature review, no new research was conducted, and no participants were recruited.

\section{Authors' Contributions}

SA: contributed to conducting a literature search on the topic of occupation, chronic stress and dementia, drafted the manuscript, and edited the final draft.

NL: contributed to conducting a literature search on the topic of income, chronic stress and dementia, drafted the manuscript, and edited the final draft. 
UNDERGRADUATE RESEARCH IN NATURAL AND CLINICAL SCIENCE AND TECHNOLOGY (URNCST) JOURNAL Read more URNCST Journal articles and submit your own today at: https://www.urncst.com

TW: contributed to conducting a literature search for the topic of education, chronic stress and dementia, drafted the manuscript, and edited the final draft.

\section{Acknowledgements}

We would like to extend a huge thank you to Sonya Kouthouridis for providing guidance as our mentor.

\section{Funding}

This study was not funded.

\section{References}

[1] What is Alzheimer's Disease? | CDC [Internet]. 2020 [cited 2020 Oct 30]. Available from: https://www.cdc .gov/aging/aginginfo/alzheimers.htm

[2] What is Alzheimer's disease? [Internet]. Alzheimer Society of Canada. [cited 2020 Oct 30]. Available from: http://alzheimer.ca/en/about-dementia/whatalzheimers-disease

[3] Chen C-L, Liang C-K, Yin C-H, Lin Y-T, Lee C-C, Chen N-C. Effects of Socioeconomic Status on Alzheimer Disease Mortality in Taiwan. Am J Geriatr Psychiatry. 2020 Feb 1;28(2):205-16. https://doi.org/ 10.1016/j.jagp.2019.06.010

[4] Tiwari S, Atluri V, Kaushik A, Yndart A, Nair M. Alzheimer's disease: pathogenesis, diagnostics, and therapeutics. International Journal of Nanomedicine. 2019;14:5541-54. https://doi.org/10.2147\%2FIJN . S200490

[5] Risk factors for dementia | Alzheimer Society of Canada [Internet]. [cited 2020 Oct 30]. Available from: https://alzheimer.ca/en/about-dementia/how-can-iprevent-dementia/risk-factors-dementia

[6] Schulz AJ, Mentz G, Lachance L, Johnson J, Gaines C, Israel BA. Associations Between Socioeconomic Status and Allostatic Load: Effects of Neighborhood Poverty and Tests of Mediating Pathways. Am J Public Health. 2012 Feb 16;102(9):1706-14. https://doi.org/ 10.2105\%2FAJPH.2011.300412

[7] Justice NJ. The relationship between stress and Alzheimer's disease. Neurobiol Stress. 2018 Feb 1;8:12733. https://doi.org/10.1016\%2Fj.ynstr.2018.04.002

[8] Bisht K, Sharma K, Tremblay M-È. Chronic stress as a risk factor for Alzheimer's disease: Roles of microgliamediated synaptic remodeling, inflammation, and oxidative stress. Neurobiol Stress. 2018 Nov 1;9:9-21. https://doi.org/10.1016\%2Fj.ynstr.2018.05.003

[9] Baum A, Garofalo JP, Yali AM. Socioeconomic Status and Chronic Stress: Does Stress Account for SES Effects on Health? Ann N Y Acad Sci. 1999;896(1):131-44. https://doi.org/10.1111/j.17496632.1999.tb08111.x

[10] Socioeconomic Status [Internet]. [cited 2020 Oct 30]. Available from: https://www.apa.org/topics/ socioeconomic-status

Anant et al. | URNCST Journal (2021): Volume 5, Issue 1 DOI Link: https://doi.org/10.26685/urncst.206
[11] Andel R, Crowe M, Hahn EA, Mortimer JA, Pedersen NL, Fratiglioni L, et al. Work-Related Stress May Increase the Risk of Vascular Dementia. J Am Geriatr Soc. 2012 Jan;60(1):60-7. https://doi.org/10.1111/j 1532-5415.2011.03777.x

[12] Karasek RA. Job Demands, Job Decision Latitude, and Mental Strain: Implications for Job Redesign. Adm Sci Q. 1979;24(2):285-308. https://doi.org/10.2307/2392498

[13] Wang HX. Work-life experience of psychosocial job stress in relation to late-life risk of dementia and Alzheimer's disease. In 2008. https://doi.org/10.1016/ j.jalz.2008.05.2121

[14] Sundström A, Sörman DE, Hansson P, Ljungberg JK, Adolfsson R. Mental Demands at Work and Risk of Dementia. J Alzheimers Dis. 74(3):735-40. https://doi.org/10.3233/jad-190920

[15] Stepkowski D, Wozniak G, Studnicki M. Correlation of Alzheimer's Disease Death Rates with Historical Per Capita Personal Income in the USA. PLoS One. 2015;10(5): e0126139. https://doi.org/10.1371\%2 Fjournal.pone.0126139

[16] Kumar H, Arokiasamy P, Selvamani Y. Socioeconomic Disadvantage, Chronic Diseases and their Association with Cognitive Functioning of Adults in India: A Multilevel Analysis. J Popul Ageing. 2020 Sep 1;13(3):285-303. https://doi.org/10.1007/s12062019-09243-9

[17] Remes O, Wainwright N, Surtees P, Lafortune L, Khaw K-T, Brayne C. Sex differences in the association between area deprivation and generalised anxiety disorder: British population study. BMJ Open. 2017 May 1;7(5):e013590. http://doi.org/10.1136/ bmjopen-2016-013590

[18] Huang C-J, Weng S-F, Wang J-J, Hsieh H-M. Competing risk analysis of the association between dementia and major depressive disorder: a nationwide population-based study in Taiwan. Aging Ment Health. 2020 Feb 3;0(0):1-7. https://doi.org/10.1080/ 13607863.2020 .1720598

[19] Liu C-C, Sun Y, Kung S-F, Kuo H-W, Huang N-C, Li $\mathrm{C}-\mathrm{Y}$, et al. Effects of physical and social environments on the risk of dementia among Taiwanese older adults: a population-based case-control study. BMC Geriatr. 2020 Jun 26;20(1):226. https://doi.org/10.1186/s12877020-01624-6

[20] Russ TC, Stamatakis E, Hamer M, Starr JM, Kivimäki M, Batty GD. Socioeconomic status as a risk factor for dementia death: individual participant meta-analysis of 86508 men and women from the UK. Br J Psychiatry. 2013 Jul;203(1):10-7. https://doi.org/10.1192/bjp.bp .112 .119479

[21] Medaglia JD, Pasqualetti F, Hamilton RH, ThompsonSchill SL, Bassett DS. Brain and Cognitive Reserve: Translation via Network Control Theory. Neurosci Biobehav Rev. 2017 Apr;75:53-64. https://doi.org/ $\underline{10.1016 / \text { j.neubiorev.2017.01.016 }}$ 
UNDERGRADUATE RESEARCH IN NATURAL AND CLINICAL SCIENCE AND TECHNOLOGY (URNCST) JOURNAL

Read more URNCST Journal articles and submit your own today at: https://www.urncst.com

[22] Stern Y. Cognitive reserve in ageing and Alzheimer's disease. Lancet Neurol. 2012 Nov;11(11):1006-12. https://doi.org/10.1016/s1474-4422(12)70191-6

[23] Qiu C, Bäckman L, Winblad B, Agüero-Torres H, Fratiglioni L. The Influence of Education on Clinically Diagnosed Dementia Incidence and Mortality Data From the Kungsholmen Project. Archives of Neurology. 2001;58(12):2034. https://doi.org/10.1001/ archneur.58.12.2034

[24] Scarmeas N. Education and rates of cognitive decline in incident Alzheimer's disease. Journal of Neurology, Neurosurgery \& Psychiatry. 2005;77(3):308-16. https://doi.org/10.1136/jnnp.2005.072306

[25] Cabral JCC, Veleda GW, Mazzoleni M, Colares EP, Neiva-Silva L, Neves VTD. Stress and Cognitive Reserve as independent factors of neuropsychological performance in healthy elderly. Ciência \& Saúde Coletiva. 2016;21(11):3499-508. https://doi.org/ $\underline{10.1590 / 1413-812320152111.17452015}$
[26] Vassilaki M, Aakre JA, Cha RH, Kremers WK, Sauver JLS, Mielke MM, et al. Multimorbidity and Risk of Mild Cognitive Impairment. J Am Geriatr Soc. 2015;63(9):1783-90. https://doi.org/10.1111/jgs.13612

[27] Villeneuve S, Belleville S, Massoud F, Bocti C, Gauthier S. Impact of Vascular Risk Factors and Diseases on Cognition in Persons with Mild Cognitive Impairment. Dement Geriatr Cogn Disord. 2009;27(4):375-81. https://doi.org/10.1159/000209965

[28] 2013 Alzheimer's disease facts and figures. Alzheimers Dement. 2013 Mar 1;9(2):208-45. https://doi.org/10.1016/j.jalz.2013.02.003

[29] Martyn CN, Pippard EC. Usefulness of mortality data in determining the geography and time trends of dementia. J Epidemiol Community Health. 1988 Jun 1;42(2):134-7. https://doi.org/10.1136/jech.42.2.134

\section{Article Information}

Managing Editor: Jeremy Y. Ng

Peer Reviewers: Sonya Kouthouridis, Ricky Chow

Article Dates: Received Nov 02 20; Accepted Dec 07 20; Published Jan 1521

\section{Citation}

Please cite this article as follows:

Anant S, Lum N, Wu T. Stress-related socioeconomic factors and risk of Alzheimer's disease: A literature review. URNCST Journal. 2021 Jan 15: 5(1). https://urncst.com/index.php/urncst/article/view/206

DOI Link: https://doi.org/10.26685/urncst.206

\section{Copyright}

(C) Swati Anant, Nicholas Lum, Tina Wu. (2021). Published first in the Undergraduate Research in Natural and Clinical Science and Technology (URNCST) Journal. This is an open access article distributed under the terms of the Creative Commons Attribution License (https://creativecommons.org/licenses/by/4.0/), which permits unrestricted use, distribution, and reproduction in any medium, provided the original work, first published in the Undergraduate Research in Natural and Clinical Science and Technology (URNCST) Journal, is properly cited. The complete bibliographic information, a link to the original publication on http://www.urncst.com, as well as this copyright and license information must be included.

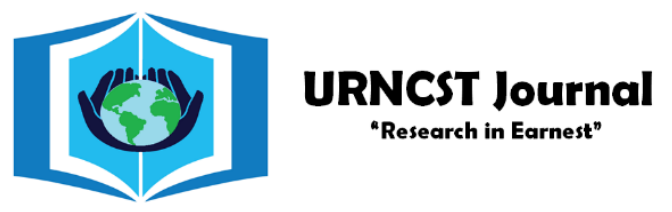

\section{Funded by the Government of Canada}

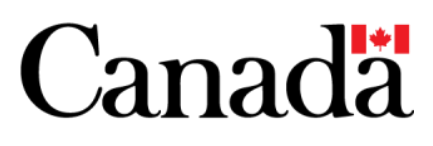

Do you research in earnest? Submit your next undergraduate research article to the URNCST Journal!

| Open Access | Peer-Reviewed | Rapid Turnaround Time | International |

| Broad and Multidisciplinary | Indexed | Innovative | Social Media Promoted |

Pre-submission inquiries? Send us an email at info@urncst.com | Facebook, Twitter and LinkedIn: @ URNCST

Submit YOUR manuscript today at https://www.urncst.com! 